\title{
VIDA FAMILIAR TRANSNACIONAL EN INMIGRANTES DE MÉXICO Y REPÚBLICA DOMINICANA EN DOS CONTEXTOS DE RECEPCIÓN
}

\section{Transnational family life in immigrants from Mexico and the Dominican Republic in two contexts of reception}

Marina Ariza ${ }^{1}$

Universidad Nacional Autónoma de México, México.

Recibido: 13 de mayo de 2011. Aprobado: 17 de octubre de 2011.

\section{RESUMEN}

Con base en una serie de entrevistas a profundidad realizadas con trabajadoras inmigrantes de México y República Dominicana en dos ciudades de inmigración -Nueva York para las mexicanas y Madrid para las dominicanas-, se exploran las pautas de interacción en tres dimensiones centrales de la vida familiar: la reproducción doméstica, la maternidad y el cuidado, y la afectividad. A pesar de las semejanzas en los patrones de interacción, emergen algunas diferencias en virtud de las disímiles estructuras familiares de los países de origen, las pautas de la migración internacional y las políticas migratorias de España y Estados Unidos como contextos de recepción.

PALABRAS CLAVE: Transnacionalidad, familia, migración.

\begin{abstract}
Based on an analysis of in-depth interviews carried out with immigrant domestic workers - Dominican women in Madrid and Mexican women in New York - this article seeks to highlight patterns of interaction in three key analytical dimensions of transnational family life: domestic reproduction, motherhood and caregiving, and emotional relationships. Despite important similarities in the patterns of interaction, certain key

Licenciada en Sociología por la Universidad Autónoma de Santo Domingo y doctora en Ciencias Sociales con especialidad en Sociología por El Colegio de México. Actualmente es investigadora titular del Instituto de Investigaciones Sociales de la Universidad Nacional Autónoma de México. Correo electrónico: ariza@unam.mx
\end{abstract}


differences emerge as a result of different family structures in the two countries of origin, patterns of international migration, and the migration policies of Spain and the United States as host countries.

KEYWORDS: Transnationality, family, migration.

\section{INTRODUCCIÓN}

Aun cuando las familias transnacionales han constituido un correlato natural de los procesos migratorios en distintos períodos históricos, las inéditas condiciones de comunicación e intercambio abiertas por el proceso globalizador conforman un entorno sui generis. Separados en ocasiones por miles de kilómetros de distancia y sólidas fronteras políticas, los integrantes de estas familias hacen uso de cuantos recursos están a su alcance para acortar las enormes distancias físicas que los separan. Factores tales como las políticas migratorias de los países de recepción, el estatus legal, el sector social de pertenencia, la antigüedad de la migración y la estructura familiar de las sociedades de origen, condicionan las posibilidades de interacción a distancia.

A partir del análisis de tres dimensiones clave de la vida familiar -reproducción doméstica, maternidad y cuidado y afectividad- en un conjunto de mujeres inmigrantes entrevistadas en dos contextos de recepción: Madrid para las dominicanas y Nueva York para las mexicanas, ${ }^{2}$ el presente artículo persigue describir las semejanzas y diferencias en sus pautas de interacción. Dos preguntas guían la reflexión: 1) ¿cómo cambia la interacción a distancia a lo largo del ciclo de vida familiar?; 2) ¿cómo inciden determinados factores contextuales (estructura familiar, rasgos de la migración internacional y políticas migratorias) en las posibilidades de interacción en las familias transnacionales de estos dos países?

La elección de dos grupos de inmigrantes de dos países latinoamericanos en dos contextos de recepción disímiles (Madrid y Nueva York), persigue profundizar en la heterogeneidad de la interacción familiar a distancia. Entre otros aspectos, las mujeres inmigrantes entrevistadas en ambos países y ciudades tienen en común el constituir una

2 Dichas entrevistas forman parte de una investigación más amplia, Migración y mercados de trabajo femeninos en el contexto de la globalización. Una perspectiva comparativa, financiada por el programa PAPIIT (IN303006) de la Universidad Nacional Autónoma de México. 
fuerza de trabajo precaria, ${ }^{3}$ por lo que las imágenes de la vida familiar transnacional que proporcionan se corresponden con la de estos sectores sociales.

\section{VIDAS FAMILIARES TRANSNACIONALES: EL CONTINUO DESAFÍO DE LA AUSENCIA}

El hiato en la interacción cotidiana abierto por la migración internacional replantea las condiciones de ejercicio de los roles familiares, desafiando los instrumentos analíticos con que habitualmente los abordamos. En los últimos años se ha desarrollado un conjunto de nociones conceptuales que procuran aprehender la complejidad de estas familias $^{4}$ (Hondagenau-Sotelo y Avila 1997; Hochschild 2001; Bryceson y Vuorela 2002; Ariza 2002; Salazar 2002; Pribilsky 2004; Baldasaar 2007; Baldasaar, Boldock y Wilding 2007; Parella 2007; Gonzálvez 2007; Skrbis 2008; Goulbourne et al. 2010).

Una rápida inspección a estos desarrollos muestra que el acento de la reflexión se coloca la mayoría de las veces en describir la manera en que sus miembros se las arreglan para mantenerse unidos preservando la cohesión y el sentido de pertenencia colectiva del que hablaban Bryceson y Vuorela (2002); unos pocos trabajos destacan los efectos desestructuradores sobre la vida familiar (Hochschild 2001; Salazar 2002, 2005). Mientras Brycson y Vuorela (2002) proponen los conceptos de "fronterizante" (frontering) y "relativizing", ${ }^{5}$ para nombrar las prácticas de creación de conexiones y de materialización de la familia como comunidad imaginada que emprenden los migrantes, Baldasaar et al. (2007) elaboran un marco analítico para entender de qué factores depende el intercambio de cuidado y apoyo moral entre padres e hijos migrantes. Para las autoras, dicho intercambio es función de la relación dialéctica entre la capacidad (habilidad) para producirlo, la obligación (en términos de normas culturales que lo prescriben) y la negociación de los compromisos familiares, condiciones que varían en virtud de las relaciones familiares, las

3 Todas las mujeres entrevistadas pertenecen a los sectores bajos manuales del mercado de trabajo, ya sea como empleadas domésticas u obreras fabriles. Véase el apartado metodológico.

$4 \quad$ Partimos de la noción de Bryceson y Vuorela (2002:3), ampliamente aceptada, según la cual se trata de familias cuyos integrantes viven una parte o la mayoría del tiempo físicamente separados, no obstante lo cual se mantienen juntos y crean un sentimiento colectivo de bienestar y unidad, aun a través de las fronteras nacionales.

$5 \quad$ Por fronterizante entienden las formas y medios que usan las familias para crear espacios y redes en terrenos en donde las conexiones afines están relativamente dispersas; relativizante alude a los modos de materialización de las familias como una comunidad imaginada (traducción propia) Brycson y Vuorela $(2002: 11,25)$. En un esfuerzo por especificar ambas nociones, Goulbourne et al. (2010:7) proponen que la primera podría referir más bien a los vínculos que en el lugar de destino establece una familia que acaba de llegar; mientras la segunda a los que sostiene con el lugar de origen. 
historias migratorias y el momento del ciclo familiar e individual (Baldasaar, Boldock y Wilding 2007; Baldasaar 2007).

Entre los mecanismos a través de los cuales las familias acortan las distancias y estructuran la interacción, las remesas ocupan un lugar señero. Además de contribuir a la reproducción doméstica, denotan la continua presencia afectiva del migrante en la cotidianeidad familiar (Sørensen 2004). En un esfuerzo por problematizarlas se han destacado sus aspectos no monetarios y la diversidad que envuelven (Levitt 2001) ${ }^{6}$ Creciente atención reciben los canales de comunicación como vehículos de narrativa social y familiar, desde el teléfono (el más ampliamente utilizado) a los videos y regalos, pasando por las fotografías (Sánchez-Carretero 2005; Carrillo 2008).

El concepto de cadenas globales de cuidado de Hochschild $(2001)^{7}$ es un antecedente importante que ha ganado relevancia en los últimos años. En su acepción original refiere a los efectos negativos sobre el bienestar de los menores de la transferencia internacional del cuidado desde el sur al norte global, como mecanismo de reproducción de las desigualdades entre ambos hemisferios (Yeats 2005). ${ }^{8}$ Dicha noción ha resultado fecunda para describir los lazos globales - no necesariamente monetarios- que unen a los migrantes y a sus familias en distintas partes del mundo (Díaz 2008). En una línea de reflexión análoga se sitúan las investigaciones que destacan el riesgo de mercantilización de las relaciones afectivas entre los menores y los padres ausentes, las tensiones emocionales y los efectos negativos sobre la intimidad familiar de la ausencia de algunas de estas figuras afectivas, casi siempre la madre (Salazar 2002, 2005; Parella 2007; Schmalbauzer 2004; Sánchez-Carretero 2005).

Entre los roles familiares es sin duda el de la maternidad a distancia el que ha acaparado la atención de los especialistas, en parte porque los primeros esfuerzos conceptuales partieron del análisis de la experiencia de las trabajadoras domésticas globales

6 Para diferenciarlas de las monetarias, Levitt (2001:54 y ss.) acuña el concepto de remesas sociales, incluyendo en ellas las estructuras normativas, los sistemas de prácticas y el capital social.

7 En palabras de Hochschild: "llamo cadenas globales de afecto o asistencia, una serie de vínculos personales entre gentes de todo el mundo, basados en una labor remunerada o no remunerada de asistencia. Normalmente estas cadenas las forman las mujeres, aunque en casos poco frecuente, solo hombres [...] Las cadenas globales... suelen comenzar en un país pobre y terminar en uno rico..." (2001:188).

8 El concepto de cadenas globales de cuidado nace de la observación de la experiencia de las trabajadoras domésticas internacionales, por lo que en sus inicios el énfasis se colocaba, tácita o explícitamente, en los vínculos transnacionales (o nacionales) entre mujeres que se sustituían entre sí en las funciones de cuidado. Para una crítica véase Yeats 2005. 
(Hondagneu-Sotelo y Avila 1997; Salazar 2001; Sánchez-Carretero 2005); unos pocos autores toman por caso el ejercicio de la paternidad (Pribilsky 2004; Dreby 2007).

Para Dreby (2007) son la naturaleza de la relación marital y el tipo de migración (individual, familiar) los factores decisivos en el tipo de interacción que se establece entre padres e hijos en familias migrantes. Parella (2007) resalta, en cambio, el papel de la clase y la posición social del migrante como elementos determinantes del grado de dependencia económica y afectiva entre este y sus familiares, aspectos que condicionan a su vez el proyecto migratorio, las estrategias económicas y la construcción de significado.

En este artículo nos centraremos en tres de estas dimensiones analíticas: la reproducción doméstica, la maternidad transnacional y el cuidado, y la afectividad, obviamente interrelacionadas. A la reproducción doméstica nos acercaremos a través del envío de remesas, pues estas constituyen sin duda el leitmotiv del proyecto migratorio en la migración no calificada de la que forman parte las trabajadoras migrantes entrevistadas. Partimos del supuesto de que dicha reproducción es una estrategia compartida y solidaria de los miembros de la unidad doméstica con el objeto de lograr la continuidad de la familia en el tiempo, estrategia que se sustenta principalmente en la reproducción cotidiana de la fuerza de trabajo (Margulis 1988:190). ${ }^{9}$ El carácter solidario no implica la ausencia del reconocimiento de las tensiones y conflictividad inherentes al mundo familiar. Se exploran la presencia de las remesas, su regularidad a través de las etapas del ciclo familiar y el objetivo al que se destinan.

Otro de los motores esenciales del proyecto migratorio en estos sectores sociales es el logro de un mayor bienestar material y social para los hijos y familiares inmediatos; de ahí que cobre relevancia analizar las pautas de interacción entre madres migrantes e hijos, o entre hijos y familiares cercanos, siempre desde la mirada de las mujeres trabajadoras. Sin apegarnos estrictamente a la noción de maternidad transnacional según fuera formulada por Hondagneau-Sotelo y Avila 1997, ${ }^{10}$ exploramos las pautas de interacción entre los hijos y las madres ausentes en diferentes momentos de la vida familiar (etapas del ciclo familiar), situación que plantean distintos desafíos para la interacción a distancia. El recurso metodológico al ciclo de vida familiar procura recuperar el dinamismo de

9 De acuerdo con este autor, además de cubrir el desgaste físico y sicológico de sus integrantes en calidad de individuos, la reproducción doméstica abarca también la reposición generacional y debe remitirse al conjunto de sus capacidades; involucra a su vez elementos ideológicos y culturales.

10 La concepción original de Hondagneau-Sotelo y Avila (1997) y Hondagneau-Sotelo (2001:94) aludía a la situación en la que las trabajadoras domésticas cuidaban a los niños de las familias americanas, mientras los suyos permanecían en los países de origen. Algunas inmigrantes tienen a una parte de sus hijos con ellas, y no todas cuidan niños en la sociedad de destino. 
la interacción familiar a través del tiempo en dos contextos migratorios específicos. Se analizan la viabilidad del cuidado y la atención de los hijos en condiciones de transnacionalidad, según son percibidos por las mujeres migrantes.

Reconociendo que las emociones son el verdadero building block de la interacción transnacional a distancia (Skrbis 2008), ${ }^{11}$ nos adentramos someramente en el terreno de la afectividad, procurando destacar los sentimientos que suscita la experiencia de la vida familiar transnacional en varios de los integrantes de estas familias. En cada una de estas dimensiones analíticas resaltamos los puntos de tensión y conflictividad que emergen.

\section{ASPECTOS CONTEXTUALES DE MÉXICO Y REPÚBLICA DOMINICANA}

Esbozaremos a continuación los rasgos esenciales de la emigración y la estructura familiar de México y República Dominicana, como aspectos contextuales que median en la interacción familiar a distancia.

Como muchos analistas han dejado establecido, uno de los aspectos que singularizan el proceso migratorio mexicano es su carácter centenario (Durand y Massey 2003; Durand 2007). República Dominicana, en cambio, tiene una historia migratoria internacional relativamente más tardía: no fue sino hasta fines de la dictadura trujillista, a principios de la década de 1960 del siglo XX, que los dominicanos iniciaron su larga tradición migratoria hacia Estados Unidos. ${ }^{12}$

En los más de 100 años de historia migratoria con que cuenta, México ha tenido prácticamente un único país de destino: Estados Unidos de América, nación que era receptora de alrededor del 90 por ciento de sus desplazamientos en el año 2010 (Instituto Nacional de Geografía, Informática y Estadística 2011a). República Dominicana, en cambio,

11 Se muestra sorprendido ante el nulo reconocimiento por parte de los estudiosos de la transnacionalidad actuales del trabajo clásico de Thomas y Znaniecki como antecedente directo de la dimensión transnacional, en particular por la relevancia que estos autores otorgaron al esfuerzo de los migrantes por mantener conexiones con los lugares de origen (Skrbis 2008:23). Skrbis apela a la necesidad de otorgar centralidad a las emociones no solo en el ámbito más acotado de las familias transnacionales, sino de la experiencia familiar en general, dando los primeros pasos hacia un marco analítico que las integre.

12 Se estima que más del 75 por ciento de la población dominicana residente en Estados Unidos se trasladó a ese país en las décadas de 1980 y 1990, siendo esta última la de mayor inmigración relativa. Durante ella, alrededor de 36.000 dominicanos por año entraron a Estados Unidos, con un pico de 51.000 en 1994 (Grammage y Schmitt 2004:16). La ciudad de Nueva York ha sido, tradicionalmente, el principal destino migratorio de los dominicanos en EUA.

22 Si Somos Americanos. Revista de Estudios Transfronterizos 
ha mostrado desde mediados de la década de 1980 una clara tendencia a la diversificación, concomitante con el fortalecimiento de las restricciones que acompañaron a la reforma migratoria de Estados Unidos en 1987, mejor conocida como IRCA (Immigration Reforma and Control Act). Aun cuando Estados Unidos continúa siendo el primer lugar de destino de la emigración dominicana, España es inequívocamente el segundo. ${ }^{13}$ La pauta de diversificación de sus desplazamientos ha continuado con ímpetu en años recientes, abarcando un mosaico heterogéneo de naciones tales como Italia, Suiza, Holanda y Alemania. ${ }^{14}$ Este aspecto, junto al elevado porcentaje de hogares dominicanos con al menos un emigrante, denota en conjunto un mayor grado de transnacionalidad de la sociedad dominicana. ${ }^{15}$

Uno de los aspectos que más llamativamente contrapone los flujos migratorios de ambos países es su distinta selectividad por sexo: mientras la emigración mexicana a Estados Unidos es fuertemente masculina, la dominicana a España es acusadamente femenina, rasgo que la singulariza en el concierto más amplio de las naciones latinoamericanas. ${ }^{16}$ En contraposición a los varios rasgos que los distancian, la emigración internacional mexicana y dominicana comparten el hecho de nutrirse principalmente de fuerza de trabajo no calificada y mostrar en las décadas recientes -al menos hasta la crisis financiera mundial de septiembre de 2008- un importante dinamismo, según lo confirma la variación positiva en el incremento porcentual relativo de sus inmigrantes en Estados Unidos y España, respectivamente. ${ }^{17}$

13 El ritmo de crecimiento de la inmigración a España desde entonces ha sido verdaderamente significativo. Datos oficiales arrojaban un total de 6.640 inmigrantes dominicanos legales en 1991. Ocho años más tarde esta cifra se había cuadruplicado hasta alcanzar los 26.854 inmigrantes (Báez 2001). Para el año 2008 el número de dominicanos con certificado de registro o tarjeta de residencia ascendía según datos oficiales a 80.973 (Boletín Estadístico de Extranjería e Inmigración 2009). No obstante, el hecho de que una parte de esta inmigración sea indocumentada dificulta la estimación real de los volúmenes.

14 Un destino históricamente importante de la emigración internacional dominicana del que no hacemos mención explícita es el de la isla de Puerto Rico, en virtud de su proximidad geográfica, así como del hecho de constituir territorio estadounidense. En tal medida lo consideramos parte de la emigración a EUA.

15 De acuerdo con las estimaciones realizadas por Maguid (2008:30) con base en los censos de la ronda del 2000, alrededor del 9,6 por ciento de los hogares dominicanos tiene al menos un integrante fuera (último censo disponible para el país); en México, el Instituto Nacional de Geografía, Informática y Estadística estima, con base en la Encuesta Nacional de la Dinámica Demográfica, un 4,4 de hogares con al menos un emigrante en el período 2004-2009 (Inegi 2011b).

16 En 2008, 62,7 por ciento de todos los dominicanos en situación de alta laboral en la Seguridad Social eran mujeres; de acuerdo con las estimaciones de Passel, en 2004 alrededor del 60 por ciento de los inmigrantes mexicanos indocumentados de 18 y 39 años eran hombres, en un contexto en el que la migración mexicana a Estados Unidos es mayoritariamente indocumentada. (Anuario de Estadísticas Laborales y de Asuntos Sociales, Ministerio de Trabajo e Inmigración, España. Disponible en http://www.mtin.es/estadisticas/anuario/TEX/ index.htm; Passel 2004).

17 Entre 2006 y 2007, dicha variación fue de 6,1 por ciento para los mexicanos en Estados Unidos, y de 14,4 por ciento para los dominicanos en España (Pew Hispanic Center, 2009; Boletín Estadístico de Extranjería e Inmigración 
En el marco de los países latinoamericanos, la estructura familiar mexicana se distingue por su alta estabilidad, el predominio de los matrimonios legales sobre las uniones consensuales, el alto porcentaje de hogares nucleares y la baja, aunque creciente, presencia de hogares de jefatura femenina (22 por ciento, en 2008, SEGOB 2010). ${ }^{18}$ República Dominicana, en cambio, y de conformidad con el llamado patrón de formación familiar caribeño, posee alta disolución conyugal, preeminencia de las uniones consensuales sobre las legales, menor importancia relativa de los hogares nucleares (del orden del 35 por ciento en el año 2002) en favor de los extensos, y porcentajes más elevados de hogares con jefatura femenina (Ariza, González y Oliveira 1994; Ariza y Oliveira 1999, 2001 y 2007). Tales rasgos de la formación familiar dominicana guardan una estrecha relación con el peso de la matrifocalidad, por oposición al patrón más patrivirilocal de la sociedad mexicana. ${ }^{19} \mathrm{Un}$ rasgo compartido por ambos países es la temprana edad a la unión (Solís y Puga 2009; Mier y Terán 2009). Estos aspectos determinan una mayor presencia de mujeres jefas de hogar en el universo de las inmigrantes dominicanas entrevistadas en Madrid. ${ }^{20}$

Como contextos de recepción de los flujos de inmigración de México y República Dominicana, Estados Unidos y España presentan diferencias sustantivas en sus políticas migratorias, las que inciden sobre la vida familiar transnacional. Si bien a partir del segundo lustro de los años 80 del siglo XX ambos países han emprendido medidas encaminadas a reforzar el control fronterizo de cara a la inmigración de los trabajadores no calificados provenientes del tercer mundo, la mayor flexibilidad relativa de la política migratoria española que ha emprendido cinco procesos de regularización desde los años 90, la existencia de mayores vías de acceso legal para la inmigración laboral no calificada, así como el tránsito relativamente expedito hacia la naturalización para el caso de los nacionales iberoamericanos en ese país (Calavita 1989 y 2006; Colectivo IOE 2002; Aja y Arango 2006), determinan que una parte sustantiva de la población dominicana

2009; los datos para España refieren a las personas que cuentan con tarjeta de residencia). Se estima que entre 19611970 y 2000-2003, la pérdida neta anual de población mexicana atribuida a la migración a Estados Unidos pasó de un promedio anual de 30 mil a 390 mil personas (Tuirán 2001; Zúñiga, Leite y Nava 2004:32). Véase Ariza y Portes 2007. Los datos del Censo Nacional de Población y Vivienda de México de 2011 indican una disminución de 31,90 por ciento en la emigración internacional mexicana entre 2000 y 2010 (Inegi 2011c).

18 Algunos de estos aspectos han comenzado a mostrar, si bien de manera todavía muy incipiente, una cierta flexibilización expresada tanto en una creciente diversificación de los tipos de hogar en detrimento del hogar tradicional biparental con hijos, como de los itinerarios conyugales (Ariza y Oliveira 2006; Solís y Puga 2009).

19 En el año 2005, en el nivel nacional, alrededor del 50 por ciento de las parejas mexicanas recién formadas residía con la familia de uno de los padres, de las cuales el 75 por ciento lo hacía con los padres de él (Mier y Terán 2009:241).

20 Con base en los datos de la Encuesta de Regularización de 1991, Oso (1998:238) señala: "República Dominicana es el que presenta una mayor proporción de trabajadores con personas dependientes ( 84 por ciento). Se trata, por lo tanto, de una migración compuesta fundamentalmente de mujeres jefas de hogar..." (1998:238).

24 Si Somos Americanos. Revista de Estudios Transfronterizos 
inmigrante en España -en oposición a la inmensa mayoría de la mexicana en Estados Unidos- cuente con estatus de residente legal. ${ }^{21}$

Este aspecto impacta decisivamente las posibilidades de interacción cara a cara entre las inmigrantes y sus familiares en origen e incide en la naturaleza de la vida familiar transnacional. En contraste con la mayoría de las mexicanas en Estados Unidos, gran parte de las dominicanas en España puede viajar libremente entre los dos (o varios) puntos que conforman el continuum de transnacionalidad, a pesar de la mayor distancia geográfica.

\section{DATOS Y METODOLOGÍA}

El análisis se sustenta en 18 entrevistas en profundidad con trabajadoras inmigrantes de México y República Dominicana realizadas en las ciudades de Nueva York y Madrid, entre mayo de 2006 y septiembre de 2007 (11 dominicanas, y nueve mexicanas), más seis entrevistas con familiares de las inmigrantes en los lugares de origen (tres de República Dominicana y tres de México), lo que comprende un total de 24 entrevistas (Los cuadros 1 a 3 resumen la información empírica). ${ }^{22}$ Con la finalidad de homogenizar la población, se seleccionó para este artículo al subconjunto de mujeres que cumpliera la condición de tratarse de familias divididas al momento de la entrevista; es decir, familias que no hubieran logrado la total reunificación de sus miembros. Se excluyó a las mujeres que migraron solteras y formaron familia en Estados Unidos o España, pues plantean una problemática distinta.

${ }^{21} \quad$ Entre el 60 y el 80 por ciento de la inmigración mexicana a Estados Unidos es indocumentada (Passel y Cohn 2008); en cambio, el porcentaje de dominicanos en situación de irregularidad en España ronda el 23,6 por ciento (Domingo y Martínez 2006:108).

22 Como fue señalado, los datos forman parte de un proyecto mayor en el que se realizaron en total más de 100 entrevistas. En todos los casos los nombres reales han sido sustituidos por nombres ficticios para preservar la identidad de las personas entrevistadas. 


\section{Cuadro No 1}

Distribución de las inmigrantes entrevistadas por etapa del ciclo familiar, condición de maternidad y país de residencia

\begin{tabular}{|l|c|c|c|c|c|}
\hline \multirow{2}{*}{\multicolumn{1}{c|}{ Ciclo familiar }} & \multicolumn{2}{|c|}{ Madres y/o abuelas } & \multicolumn{2}{c|}{ No madres $^{* * * *}$} & \multirow{2}{*}{ Total } \\
\cline { 2 - 5 } & Madrid & Nueva York & Madrid & Nueva York & \\
\hline Etapa temprana $^{*}$ & 2 & 2 & 1 & 1 & 6 \\
\hline Etapa de consolidación $^{* *}$ & 2 & 2 & & ---- & 4 \\
\hline Etapa avanzada $^{* * *}$ & 4 & 2 & 2 & ---- & 8 \\
\hline $\begin{array}{l}\text { Entrevistas con familiares } \\
\text { en origen }\end{array}$ & 2 & 2 & 1 & 1 & 6 \\
\hline Total & 10 & 8 & 4 & 2 & 24 \\
\hline
\end{tabular}

${ }^{\star}$ Hijos menores de 13 años. ${ }^{* *}$ Hijos de entre 13 y 18 años. ${ }^{* *}$ Hijos mayores de 19 años. ${ }^{* * *}$ En el caso de las no madres el criterio de clasificación es la edad de la entrevistada (temprana: menos de 30 años; de consolidación o media: entre 30 y 44; avanzada: 45 o más).

La estrategia metodológica siguió dos caminos complementarios: 1) la indagación exhaustiva en las ciudades de destino de la trayectoria pre y posmigratoria de las trabajadoras, una detallada descripción de la secuencia laboral antes y después de la migración, con especial atención al servicio doméstico; y una recopilación de los cambios ocurridos en la estructura familiar a raíz del desplazamiento, así como de las redes y vínculos transnacionales, cuando los hubiere. 2) Recorridos etnográficos por las localidades de origen y entrevistas seleccionadas con algunas familias de las mujeres como una manera de triangular la información.

\section{Cuadro No 2}

Distribución de las inmigrantes entrevistadas por tipo de hogar antes de migrar y país de origen

\begin{tabular}{|l|c|c|}
\cline { 2 - 3 } \multicolumn{1}{c|}{} & \multicolumn{2}{c|}{ País de origen } \\
\hline \multicolumn{1}{c|}{ Tipo de hogar antes de migrar } & República Dominicana & México \\
\hline Nuclear jefe varón & 3 & 5 \\
\hline Nuclear jefe mujer & 6 & 2 \\
\hline Extenso jefe varón & 1 & --- \\
\hline Extenso jefe mujer & 1 & --- \\
\hline Total & 11 & 7 \\
\hline
\end{tabular}


El guión de la entrevista recogió información sobre tres aspectos centrales: a) el proceso migratorio en sí mismo y los vínculos transnacionales; b) una detallada reconstrucción de la trayectoria laboral en origen y destino con especial atención al empleo en el servicio doméstico, incluyendo un subconjunto de obreras fabriles como elemento de contraste; c) una secuencia de los cambios familiares que acompañaron a la migración, indagando acerca de las relaciones familiares a distancia, sus interacciones con el proceso migratorio y la percepción general de las mujeres del impacto de la migración sobre el bienestar de sus hijos.

\section{Cuadro No 3}

Distribución de las inmigrantes entrevistadas por estado conyugal al momento de la entrevista y país de residencia

\begin{tabular}{|l|c|c|c|c|c|c|}
\cline { 2 - 7 } \multicolumn{1}{c|}{} & \multicolumn{2}{c|}{ Madrid } & \multicolumn{2}{c|}{ Nueva York } & \multicolumn{2}{c|}{ Total } \\
\hline $\begin{array}{c}\text { Estado } \\
\text { conyugal }\end{array}$ & Número & Porcentaje & Número & Porcentaje & Número & Porcentaje \\
\hline Soltera & 2 & 18,2 & 1 & 14,2 & 3 & 16,7 \\
\hline $\begin{array}{l}\text { Unida o } \\
\text { casada }\end{array}$ & 2 & 18,2 & 4 & 57,1 & 6 & 33,5 \\
\hline $\begin{array}{l}\text { Divorciada o } \\
\text { separada }\end{array}$ & 6 & 54,6 & 2 & 28,5 & 8 & 44,6 \\
\hline Viuda & 1 & 9,0 & & & 1 & 5,1 \\
\hline Total & 11 & 100,0 & 7 & 100,0 & 18 & 99,9 \\
\hline
\end{tabular}

Las inmigrantes fueron ubicadas a través del procedimiento de bola de nieve, procurando diversificarlas en términos sociodemográficos. El período de referencia fue el mismo para ambos países: que hubieran llegado a la ciudad entre 1986 y 2006. Este criterio de uniformidad temporal se relaciona con el inicio de la oleada reciente de inmigración latinoamericana a España, y con el momento en que emerge la ciudad de Nueva York como destino importante para la inmigración mexicana: ambas corrientes migratorias arrancan en un lapso similar (1980 en adelante), tratándose en los dos casos principalmente de migración no calificada. Como fue señalado, a pesar de haber arribado a las ciudades destino en un lapso histórico similar, mexicanos y dominicanos poseen perfiles opuestos en cuanto al carácter regular o irregular de la migración: altos porcentajes de irregularidad entre los mexicanos, en contraste con los dominicanos en España. La selección de los países y ciudades se sustenta en los siguientes aspectos: 1) España y Estados Unidos constituyen los principales destinos internacionales de la emigración latinoame- 
ricana; 2) en virtud de sus políticas migratorias y otra serie de aspectos (ubicación e importancia geopolítica, idioma, cultura, mercados de trabajo), ambos países conforman contextos de recepción disímiles.

Dos recursos metodológicos guían el análisis de los datos en cada una de las tres dimensiones analíticas (reproducción doméstica, maternidad y cuidado, y afectividad): 1) la distribución de las entrevistadas por etapa del ciclo familiar; 2) la antigüedad de la migración; es decir, la duración de la separación. En general, estos aspectos están relacionados, pues las mujeres ubicadas en el ciclo temprano suelen tener historias migratorias relativamente cortas, por oposición a las del ciclo avanzado, aunque hay excepciones. El ciclo de vida familiar es una estrategia metodológica de gran utilidad para aprehender retrospectivamente la naturaleza cambiante del núcleo familiar a través del tiempo (Hill 1964). ${ }^{23}$ No obstante, sus distintas etapas deben ser tomadas como construcciones analíticas que permiten captar variaciones dentro de la estructura familiar, antes que como secuencias normativas (Ariza y Oliveira 2004).

\section{FACETAS DE LA VIDA FAMILIAR TRANSNACIONAL}

En el análisis de la información empírica que a continuación emprendemos partimos del supuesto de que la dinámica de las familias transnacionales oscila entre procesos que promueven su cohesión e integridad, y otros que la amenazan, en una suerte de equilibrio inestable en el que intervienen muchos factores (Ariza 2002). Las políticas migratorias de los países receptores, el sector social de pertenencia, las necesidades marcadas por el momento del ciclo familiar, el tipo de migración, son parte de los elementos que condicionan el tipo de interacción posible.

En las dos primeras dimensiones analíticas (reproducción doméstica, maternidad y cuidado), nos valemos del contraste entre las distintas etapas del ciclo de vida familiar para captar la diversidad de circunstancias por las que atraviesan; en la tercera (afectividad), nos apoyamos en la duración de la separación como recurso heurístico, resultó un

23 En su formulación original, Hill (1964) proponía 11 etapas, desde la unión conyugal hasta la salida de los hijos del hogar, la llamada "etapa del nido vacío". Desde un punto de vista técnico, y en virtud de la información empírica de que disponemos, utilizamos la clasificación operativa de la Comisión Económica para América Latina (CEPAL), simplificándola. Así, las mujeres en ciclo temprano y de expansión, que en adelante llamaremos solo temprano, tienen hijos menores de 13 años; las del ciclo de consolidación tienen hijos de entre 13 y 18 años; y las del avanzado, mayores de 19. En realidad, la CEPAL combina la edad de la madre con la del hijo más pequeño; nosotros tomamos solo este último criterio. 
criterio con mayor capacidad de discriminación. En el orden de exposición referimos en primer lugar los factores comunes a las familias transnacionales de ambos países, para destacar en un segundo momento las diferencias encontradas.

\section{Los avatares de la reproducción doméstica}

"... Armando lo único que hizo fue una barda..."

(Carmencita, madre de una inmigrante en Nueva York, estado de Morelos, México)

“... Muy bien que ellos estén estudiando, pero yo llevo cuatro años sin un duro..."

(Yolanda, dominicana, 14 años en Madrid, ciclo familiar avanzado)

El principal indicador del que nos valemos en esta dimensión es el envío o no de remesas monetarias, su regularidad y a qué aspecto de la reproducción doméstica se destinan aquellas, resaltando las tensiones que suscitan. Sin excepción, todas las inmigrantes entrevistadas en ambos países remiten dinero a sus lugares de origen y unas pocas envían también remesas no monetarias. Aunque existen algunas excepciones, grosso modo tiene lugar una relación curvilineal entre el ciclo familiar y el envío de remesas: estas son sistemáticamente mayores entre la etapa temprana y la de consolidación, y menores en la fase avanzada, cuando los hijos han formado un hogar independiente.

En la regularidad de las remesas incide, además del momento del ciclo familiar, la condición de maternidad. Como era de esperarse, el envío es más constante en las mujeres que son madres en etapa temprana o de consolidación, ya sea que tengan o no cónyuge. Suele ser más relevante también en las fases iniciales de la migración, aspecto que guarda una relación de concomitancia con el momento del ciclo dado el determinante fuertemente laboral de los desplazamientos migratorios. En el universo de nuestros casos son los familiares cercanos: la madre, la hermana, el mayor de los hijos, el yerno o la suegra, quienes fungen como administradores de las remesas.

Tres son los destinos principales de las remesas en la generalidad de las situaciones: 1) el apoyo en la manutención cotidiana de los hijos o familiares cercanos y en los gastos extraordinarios que puedan surgir; 2) la inversión en infraestructura o en la construcción de una casa; 3) el ahorro en instituciones bancarias en el país de origen. Cuando las mujeres son jóvenes y solteras, aunque el dinero sea administrado por los padres o parientes cercanos, el proyecto material tiende a ser individual. En las etapas avanzadas del ciclo familiar suele disminuir el envío regular de remesas para la manutención de los 
hijos, máxime si estos han concluido sus estudios y han logrado independencia económica. Pero aunque empiezan a ser más eventuales, en realidad nunca cesan del todo. En particular, hay un subgrupo de inmigrantes integrado por dominicanas jefas de hogar, que retomaremos más adelante, que continúa con la pauta de enviar remesas regulares a lo largo de toda la vida. En ocasiones, el hecho de que disminuyan las necesidades de los hijos que permanecieron en el lugar de origen da paso a la emergencia de proyectos económicos de carácter más personal en las migrantes que son madres.

Las necesidades de la vida cotidiana que las remesas cubren son muy variadas y van desde los gastos de la educación de los hijos, a los de vestimenta y calzado, y cualquier otra eventualidad que surja. Se destinan también a eventos extraordinarios, tales como enfermedades, gastos funerarios y rituales familiares (bautizos, graduaciones, 15 años, etc.). Para estas inmigrantes, provenientes en su mayoría de sectores sociales bajos, la construcción de la casa en el país de origen es el proyecto de largo plazo que materializa el éxito de la migración como empresa. Pero en lo que el sueño de la construcción de la casa propia llega a materializarse, cualquier inversión, ya sea en infraestructura o en enseres domésticos, cumple la función de legitimar el alto costo afectivo que la migración envuelve. Así, Laura, una joven dominicana de 22 años de edad, con poco tiempo de residencia en Madrid y en etapa temprana del ciclo familiar, reconoce que decidió enviar dinero para la construcción de un muro en el hogar de sus padres con quienes dejó a su hija de cuatro años para demostrar que "...yo estoy aquí para algo... ¿ ¿no?...”.

De los datos emerge que las remesas se erigen en un factor de diferenciación interna entre quienes resultan beneficiarios y quienes no, encerrando situaciones potencialmente conflictivas. Algunas de estas desavenencias se suscitan cuando, por ejemplo, hay discrepancias entre el destino que las migrantes dieron a las remesas y aquel en que efectivamente fue empleado, sobre todo si va en detrimento del bienestar de los menores. En ocasiones el conflicto sobreviene cuando la inmigrante se percata del franco hurto del dinero enviado, lo que es percibido como traición a la confianza depositada. En las familias transnacionales de ambos países encontramos algunas estrategias defensivas de las mujeres ante la excesiva demanda económica, real o anticipada, de los familiares en origen, las que van desde ahorrar a escondidas del resto de los familiares, hasta entrar en complicidad con alguno de ellos para que oculte a los demás la llegada de las remesas monetarias, pasando por acceder a la solicitud de envío de dinero con la condición de que, en vez de una dádiva, se reciba en calidad de préstamo. Aunque minoritarias, estas conductas denotan la capacidad de agencia y resistencia de las mujeres migrantes ante las continuas demandas de algunos familiares, pues dentro de la poderosa mitología que rodea a la migración está la creencia de que el dinero abunda y se consigue con facilidad. 
En contextos de fuerte privación social, el envío de remesas deviene tanto un factor de estructuración de la interacción entre el migrante y sus familiares, como una expresión del afecto e interés por ellos (Sørensen 2004). La interacción a partir de las remesas puede incluir elementos de manipulación y chantaje, y desembocar en la mercantilización de la relación afectiva (Salazar 2002, 2005; Sánchez-Carretero 2005; Dreby 2006). Algunas de estas pautas de conducta se inscriben dentro de los dos tipos de triángulos relacionales descritos por Sánchez-Carretero (2005): el de amor-dinero-distancia y el de sacrificiochantaje-distancia. En virtud del primero, el dinero se constituye en el medio por excelencia de expresión del amor (cuanto más, mayor), mercantilizando el vínculo afectivo; en el segundo, la retórica de la migración como una empresa heroica que envuelve el sacrificio tanto de los que migran como de los que permanecen, otorga derecho moral para manipular la relación afectiva y obtener algo a cambio. En los relatos de nuestras entrevistas encontramos ambas cosas: niños que expresamente manipulan el sentimiento de culpa de las madres para que les envíen más obsequios materiales, y madres que conscientemente utilizan los objetos materiales logrados (o por lograr) para legitimar el proyecto migratorio o la ausencia de alguna figura afectiva central (el padre o la madre). Así, cuando en los largos años de separación por los que atravesó su familia, Oralia, una niña mexicana llegaba llorando donde su madre porque en la escuela se burlaban de ella diciéndole que no tenía papá, su madre, Raquel, la reconfortaba exclamando: “... ¿ ¿y quién te envía todas esas muñecas?.... A su vez, Laura, la joven dominicana previamente referida, justificaba ante su hija de apenas tres años su inminente partida al decirle que "...era para comprarle un coche cuando ella tuviera 15 años...."

Tienen lugar situaciones en las que las madres utilizan expresamente el envío de remesas a otros miembros de la familia como medio para asegurarse de que estos prodiguen el cuidado y la atención adecuados a los menores. Así, Juana, una de las entrevistadas en etapa de consolidación del ciclo familiar y con apenas un año de residencia en Madrid, admite francamente: “...yo los compro.... Y es que la preocupación por el bienestar de los hijos es un elemento central en el discurso de las mujeres. En algunas ocasiones, los menores se constituyen en verdaderos rehenes, pues son la garantía de que los recursos van a llegar. ${ }^{24}$ En otras, se cometen abusos en contra de ellos al ocultarles que el dinero llegó, desviarlo, emplearlo con otros fines o redistribuirlo entre todos los menores - propios y ajenos- que la cuidadora tiene a su cargo. ${ }^{25}$

24 Este dato emerge tanto de las entrevistas con las mujeres como de las sostenidas con informantes clave en instituciones de atención a los menores en comunidades altamente expulsoras de México.

25 Jerónimo, un niño mexicano entrevistado en el estado de Puebla, cuya madre había migrado sola largo tiempo atrás, relata que durante mucho tiempo en su infancia ignoró que su madre le había enviado regularmente dinero. Nunca se lo dijeron ni a él, que era el más chico, ni a sus hermanos, lo que llevó a la madre a tomar la decisión de que los niños vivieran solos. 
Dos diferencias surgieron en esta dimensión analítica entre las familias, mexicanas y dominicanas: 1) un patrón de envío regular y permanente de remesas a lo largo de la vida en un subconjunto de las mujeres dominicanas jefas de hogar para socorrer cualquier eventualidad, aún en detrimento de sus condiciones de vida; 2) una pauta de relevo transnacional en el envío o recepción de las remesas por algún familiar residiendo en otro país (usualmente Estados Unidos), también en las dominicanas, cuando por alguna razón ellas no pueden generar los recursos suficientes. En nuestra hipótesis, el primer aspecto se relaciona con el peso de la jefatura de hogar femenina en la estructura familiar del país, lo que las obliga a prolongar el rol de proveedoras por muchos años. ${ }^{26} \mathrm{El}$ segundo aspecto denota más bien el importante grado de transnacionalidad de la migración dominicana dada la mayor diversificación de sus destinos migratorios, en contraste con México, según hemos referido. Esta condición de mayor transnacionalidad relativa permite a los migrantes internacionales dominicanos potenciar las posibilidades de generación de ingreso y de apoyo mutuo entre más de un país de residencia, además del propio.

\section{Maternidad y cuidado}

“... No me sentía a gusto con mi familia porque no me trataban bien a mis hijos..." (Mónica, dominicana, seis años en Madrid, fase de consolidación)

“....pues está mi suegra para echarles su ceja...."

(Anastasia, mexicana, 9 años en Nueva York, fase de consolidación)

Este apartado incluye información empírica relativa a mujeres que son madres (14 de las 18) y a otras que no lo son. En el caso de las primeras abordamos la percepción de las entrevistadas sobre la posibilidad de ejercer la maternidad en condiciones de distancia física a causa de la migración y cuál entienden ha sido el impacto de la ausencia de ellas en el bienestar de los hijos que quedaron atrás; indagamos también si reportan problemas en el desempeño escolar de los menores o en su conducta. En el subconjunto de las mujeres que no son madres (4), resaltamos el apoyo brindado a los progenitores o a otros familiares.

26 A sus 59 años, Beatriz, con 12 años de residencia en Madrid y en la etapa avanzada del ciclo familiar, exclama con orgullo: “...yo me moriré trabajando para ellos, todavía trabajo... para ellos trabajo...”. Aunque ha cubierto la mayoría de las necesidades de sus ocho hijos y tiene a la mitad de ellos residiendo consigo en Madrid, solventa ahora (momento de la entrevista) las necesidades de varios de sus nietos en la localidad de origen. 
La distinción por etapa del ciclo familiar al momento de la entrevista permite observar los efectos diferenciales sobre los menores en edades sucesivas, una suerte de instantáneas fotográficas del impacto de la migración en distintas unidades familiares que, si las enlazamos, nos proporcionan una mirada panorámica conformando una suerte de cohorte ficticia. Así, las mujeres en una fase temprana de ciclo familiar tienen entre 22 y 31 años edad, con hijos de entre tres y diez años. Llevan en conjunto entre nueve meses y tres años residiendo en las ciudades de destino, y todas han dejado a sus hijos atrás a cargo de la familia materna. Tres de ellas son jefas de hogar (dos dominicanas y una mexicana), la restante es esposa (mexicana) del jefe del hogar, al que siguió varios años después de que él migrara.

Todas estas mujeres, con excepción de una, manifiestan cambios en la interacción con los hijos a raíz de la migración. En ocasiones, los menores evaden hablar con ellas en el teléfono o, aparentemente turbados y poco comunicativos, turnan rápidamente el auricular a otros adultos cercanos. Esta conducta forma parte del patrón de "indiferencia fingida" del que habla Dreby (2007) como reacción frecuente en los niños preadolescentes en familias migrantes. Una de las dos madres que verbalmente minimizaron el efecto de la migración sobre los hijos resultó refutada por la abuela de los menores (madre de la inmigrante), entrevistada en la localidad de origen (México). La señora, a cuyo cargo estaban los dos menores, expresó que ambos quedaron visiblemente afectados por la ausencia materna, sobre todo la más pequeña. Otro cambio en la conducta, también descrito por Dreby (2007), es la tendencia a nombrar a la abuela "mamá", o a mostrar cierta confusión respecto de quién es la figura materna, hecho que causa profunda desazón en las migrantes, como vívidamente lo expresa Leticia, una mexicana de 31 años de edad, ubicada en la etapa temprana del ciclo familiar y con poco menos de dos años en Nueva York: “...tengo miedo a que mis hijos se adapten más a mis padres que a mí...”.

En las madres que se encuentran en la etapa de consolidación, cuyos hijos están en plena adolescencia (13 a 18 años), predominan problemas de autoridad, falta de disciplina, desobediencia, bajo rendimiento escolar o apatía. En palabras de alguna de ellas, los hijos se ponen "berrinchudos" y es necesario hablarles "fuerte". Suelen atribuir el comportamiento al excesivo consentimiento de los abuelos para con los nietos. En la medida en que carecemos como elemento de control de entrevistas con mujeres no migrantes con hijos en edades similares, es imposible saber si la conducta señalada es producto de la ausencia materna o simplemente de la adolescencia. Una hipótesis plausible es que sea 
el producto de la interacción de ambos procesos agravada por el ambiente de relativa laxitud que algunas madres atribuyen a la crianza de los abuelos. ${ }^{27}$

Otra es la problemática expresada por las seis mujeres situadas en la fase avanzada del ciclo familiar, todas ellas de más de 45 años de edad, con hijos de 19 o más, y casi siempre abuelas. ${ }^{28}$ Con excepción de un caso en el que el apoyo económico de la madre viuda a la formación universitaria de sus hijos es todavía decisivo, la etapa de crianza de los hijos ha culminado, por lo que las preocupaciones que verbalizan refieren más a los problemas propios de la vida adulta independiente: desavenencias conyugales, éxitos o fracasos laborales, apuros monetarios, crianza de los nietos. El rol activo de la maternidad se ha atenuado en términos generales, pero no deja de estar presente. Aun en esta etapa tardía, dos mujeres dominicanas tomaron la decisión radical de llevar consigo a los hijos a Madrid como medida extrema para encausar la conducta ante la negativa de ellos de seguir estudiando. Este recurso es relativamente menos probable entre las inmigrantes mexicanas, debido a su carácter mayoritariamente indocumentado, pero no está ausente. Tiene lugar también el mecanismo inverso: enviarlos de vuelta al país de origen para que los abuelos o parientes los disciplinen. Una última estrategia es el retorno definitivo de la madre jefa de hogar para tomar la rienda de los hijos cuando la salud o la avanzada edad de los abuelos les impiden hacerlo.

Uno de los aspectos sistemáticamente indagados con las entrevistadas fue el hecho de si ellas estimaban que era factible ser madres a distancia. ${ }^{29}$ Los resultados muestran las tensiones que la separación familiar introduce en la autoestima de las mujeres por la inevitable contraposición entre el fuerte peso normativo de la maternidad como valor social y las limitaciones que a su ejercicio impone la migración. Invariablemente, la primera respuesta era un sí claramente defensivo, para ir atemperando la afirmación inicial en el curso de la conversación hasta admitir de forma ambivalente lo poco que podía lograrse. Los siguientes fragmentos ilustran parte del argumento: “...pues está mi suegra para echarles su ceja... prácticamente se fueron criando solos...” (Anastasia, Nueva York,

27 De las cuatro mujeres que pertenecen a este grupo, dos (mexicanas) dejaron a los hijos a cargo de las familias materna y paterna, respectivamente; las otras dos (dominicanas) los dejaron al cuidado del ex marido en un caso, y de la hermana en el otro. Todas las dominicanas son jefas de hogar, las mexicanas son cónyuges del jefe, aunque una de ellas migró siendo jefa y volvió a unirse en la ciudad de destino (Nueva York). La antigüedad de la migración entre estas mujeres oscila entre los seis y los nueve años.

28 Este grupo está conformado por dos mexicanas y cuatro dominicanas. Estas últimas son jefas de hogar, de las mexicanas una lo es; la otra es esposa del jefe en un hogar nuclear. Con dos excepciones, la mayoría tiene más de 12 años de residir en el país de destino. Es frecuente que se encuentren en una situación de reunificación parcial de sus familias, con algunos de los hijos residiendo con ellas en Madrid o Nueva York, y otros en las comunidades de origen.

29 Se inquirió también si ellas entendían que era posible "controlar" la conducta de los hijos a distancia.

34 Si Somos Americanos. Revista de Estudios Transfronterizos 
fase de consolidación del ciclo familiar, 10 años sin ver a los hijos que quedaron atrás). “...confío en mis padres, ellos son los que se encargan de ella y de la educación... es que aquí no puedo hacer mucho o nada..." (Laura, Madrid, ciclo familiar temprano, nueve meses en Madrid).

Otra conducta que expresa las tensiones que en las mujeres ocasiona infringir el sentido normativo de la maternidad, es la práctica de evadir comunicar a los hijos pequeños que ellas van a migrar, dejando que el peso de las circunstancias les haga entender la situación. Esta resultó una pauta recurrente en una parte de las inmigrantes de ambos países, hecho que desconcierta y afecta mucho a los menores. En estas situaciones, las mujeres simplemente no encuentran el valor suficiente para enfrentarlos y, en cierto modo, huyen. ${ }^{30}$

En cuanto a las diferencias entre países en esta dimensión analítica, encontramos una actitud más restrictiva hacia la movilidad de las mujeres en las familias transnacionales mexicanas que dominicanas, en sentido general, sobre todo si son madres y al partir dejan a los hijos. Varias de las entrevistadas mexicanas evocaron la oposición inicial de sus padres a la migración. Así, Lupe, la madre de Leticia, recuerda el comentario que le hicieron a su hija cuando esta les planteó que se iría al Norte, una vez que el marido -también migrante- la hubiera abandonado: “...le pedimos mucho a Dios que ella no se olvide de sus hijos [...] Tú como madre, no te vayas a olvidar de ellos...”

En contraste, entre las dominicanas la ausencia de un marido legitima la partida de la madre jefa de hogar. La hermana de Beatriz, entrevistada en Azua, República Dominicana, entiende que está bien que ella se fuera porque “...es una mujer que no tiene marido..."; en otras palabras, no tiene quién la provea. En nuestra hipótesis, el carácter predominantemente femenino de la migración internacional dominicana a España, el peso importante de la jefatura de hogar femenina y la mayor transnacionalidad del conjunto de su sociedad, parecen conformar un ambiente cultural favorable o abiertamente instigador de la migración independiente de mujeres, precisamente por el hecho de ser madres, aunque no solo por ello. Se recogen en los relatos de las inmigrantes dominicanas en Madrid situaciones en las que los padres estimulan a las hijas y hermanas a emigrar, aunque a veces ellas no lo hayan contemplado. En las localidades rurales mexicanas, en cambio, el patrón de patrivirilocalidad prescribe que al casarse -si los cónyuges no forman un hogar independiente- pasan a residir con los padres del esposo; si este sale hacia el Norte las esposas quedan a resguardo de los suegros. Este aspecto restringe mucho la

30 Los efectos de esta práctica en el bienestar síquico de los menores pueden ser desastrosos. Una informante clave entrevistada en una localidad de expulsión de República Dominicana, relató el largo período depresivo por el que atravesó una menor a la que su madre dijo: “...mi hija, adiós, vuelvo ahora...”, y pasaron más de 15 años. 
movilidad e independencia de las mujeres que permanecen en las localidades de origen, quienes han de pedir permiso a las suegras o al marido ausente cuando se comunica telefónicamente, para desplazarse fuera del ámbito doméstico (D’Aubeterre 2000; Ariza y D’Aubeterre 2009). ${ }^{31}$

En el subconjunto de las mujeres que no son madres (una mexicana y tres dominicanas) el apoyo y el cuidado de las inmigrantes se canaliza principalmente hacia los progenitores sobrevivientes o hacia otros familiares (hermanas, sobrinos). Situaciones críticas como la enfermedad de los progenitores intensifican la comunicación telefónica y estimulan el desarrollo de estrategias colectivas para asegurar el cuidado de los familiares en el lugar de origen. Así, Dulce, una inmigrante dominicana que entró al servicio doméstico con la esperanza de poder en un futuro cercano ejercer en Madrid su profesión de odontóloga, se coordina con sus hermanos en Santo Domingo y Nueva York para cubrir los gastos de la enfermedad de su madre, algo que le suscita un profundo sentimiento de orgullo. Piensa que tener la posibilidad de contribuir a solventar los gastos de atención médica de su madre es de las pocas cosas que ha logrado con la migración. Además de los padres, los sobrinos, las hermanas y otros familiares cercanos suelen ser depositarios de la atención y el cuidado a distancia de estas mujeres migrantes que no tienen descendencia. La ausencia de la maternidad confiere un tono algo más ligero a sus narrativas, en las que no aparece la sensación de agobio que ocasiona el peso de la responsabilidad familiar. La situación de salud de los padres, el miedo a que fallezcan estando ellas ausentes o la culpa por no haberse encontrado junto a ellos a la hora de la muerte, son preocupaciones frecuentes en los relatos en este grupo de mujeres y, en general, en el conjunto de las entrevistadas.

\section{Afectos y desafectos: el prolongado hiato de la ausencia}

“... ¿Qué familia somos? No somos una familia..." [refiere el reclamo del hijo]. (Raquel, 49 años, 13 años en Nueva York, etapa avanzada del ciclo familiar)

“... A ellos les ha faltado el cariño y yo me he perdido la juventud de mis hijos..." (Yolanda, dominicana, 55 años, 14 años en Madrid, etapa avanzada del ciclo familiar)

31 El patrón tradicional de la migración mexicana a Estados Unidos era el del jefe varón que migraba y regresaba cíclicamente a su lugar de origen. Este patrón echó raíces en el conocido programa Bracero, mediante el cual los hombres mexicanos suplieron las necesidades de mano de obra de la agricultura del sur de Estados Unidos entre 1940 y 1962. De 1980 en adelante ha crecido consistentemente la participación femenina en los flujos de emigración (Durand, Massey y Zenteno 2003). En nuestras entrevistas figuran casos tanto de migración femenina asociacional -siguiendo los pasos del marido migrante-como de migración femenina independiente. 
Nos referiremos en este apartado a las repercusiones afectivas de la migración desde la mirada de las mujeres entrevistadas. Utilizamos como indicadores la frecuencia de la comunicación, el sentido de pertenencia, ${ }^{32}$ y la valoración general de la experiencia de la migración en términos de sus ganancias y pérdidas.

Independientemente del momento del ciclo familiar y de la antigüedad de la migración, todas las mujeres mantienen una comunicación fluida con sus hijos y parientes en el lugar de origen, esencialmente a través del teléfono, hablando al menos una vez a la semana. Es característico que la frecuencia de las llamadas sea mucho mayor entre las de reciente arribo y disminuya a una o dos veces por semana con el paso del tiempo. El sentido de pertenencia medido a través del indicador ¿dónde se siente usted mentalmen$t e$ ?, presenta pocas variaciones: ninguna de las inmigrantes dijo sentirse plenamente en el lugar de destino; priman más bien los enunciados de "estar totalmente allá" o "estar dividida", a pesar de la antigüedad de la migración. El "estar dividida" es más frecuente entre quienes, aparte de sus hijos, en la ciudad de destino, han formado otra pareja o han procreado nuevos hijos. Así, Anastasia dijo sentirse literalmente dividida porque tenía "... dos hijos allá y dos aquí...", a los que dejó en Puebla, México, cuando se desplazó a Nueva York, siguiendo los pasos del marido. Lo mismo exclamó Claudia, una dominicana con 14 años de residencia en Madrid y en etapa avanzada del ciclo familiar, pues gracias al proceso de reagrupamiento familiar había podido traerse a uno de sus hijos pero los demás, casados y con familia propia, habían preferido quedarse en República Dominicana; enfáticamente expresó: “....ahora sí estoy jodida...”.

Los hallazgos de investigación muestran que en esta dimensión de la vida familiar, la antigüedad de la migración es una variable con mayor capacidad de discriminación que el momento del ciclo familiar. En la narrativa de las mujeres que tienen pocos años de haber migrado (tres o menos) -usualmente ubicadas en la etapa temprana- hay trazas más evidentes del proceso de duelo que conlleva la separación, así como marcados sentimientos de dolor y culpa, que suelen ser mitigados al colocar al retorno como un escenario próximo. Refieren con frecuencia sentimientos depresivos (tristeza, pesar, llanto, falta de apetito, pérdida de peso). Sin duda, el aspecto más difícil de manejar de todos es la separación de los hijos, algo que no pueden evitar sentir como abandono, con la consiguiente autoculpabilización. La diferencia con las mujeres que llevan más tiempo residiendo en las ciudades de inmigración (10 o más años), es que en estas predomina un sentimiento de resignación.

32 Para ello se les preguntó en qué lugar se sentían mentalmente más presentes, si en el país de origen o en el de destino. 
La valoración del peso de la migración en sus vidas muestra que dos son los elementos que se colocan en la balanza: el logro económico y la afectividad. Como los resultados del primero distan mucho de las expectativas iniciales, y sus condiciones de vida y trabajo siguen siendo precarias, no obstante haber logrado o iniciado la construcción de una casa ( $\mathrm{y}$ a veces dos), predomina en las entrevistadas el balance negativo de la migración ante lo que entienden es la gran pérdida: la afectividad. Es así como Deyanira, una dominicana soltera de 56 años con seis en Madrid pero con una larga trayectoria migratoria que inició en Venezuela, reconoce: “...he ganado en lo económico, pero he perdido por estar tanto tiempo lejos de mi familia [...] Ha muerto mi madre estando yo aquí. He perdido...”.

Evaluada contra el rasero de la afectividad, la migración difícilmente resulta ganadora en los relatos de estas mujeres de escasos recursos y condiciones laborales precarias, con largas y esforzadas trayectorias de trabajo. Como fue señalado, las madres de hijos pequeños con períodos de residencia relativamente cortos (menos de 3 años), en Madrid o Nueva York, refieren la pérdida de comunicación con sus hijos, a pesar de las frecuentes llamadas, así como los límites que a una comunicación sustantiva, profunda, opone el teléfono.

Aunque reconocibles desde los inicios mismos del proceso migratorio, las secuelas de la migración sobre la dimensión afectiva resultan claramente patentes en aquellas familias que han transitado por separaciones prolongadas, las que dan lugar a procesos de desfamiliarización, de extrañamiento respecto de las figuras afectivas a las que normativamente se debe querer pero con las que no se ha convivido por muchos años. Tal es el caso de la familia de Raquel, una inmigrante mexicana originaria de Oaxaca, con 13 años de residencia en Nueva York. Raquel estuvo separada de su marido 17 años a causa de la migración, de los 34 que llevan casados. El esposo se fue por un año cuando el primer hijo tenía 6 meses y pasaron 12 para que ella pudiera cruzar la frontera como migrante indocumentada, con todos sus hijos, e intentar la reunificación. Al no poder sobrevivir económicamente en Nueva York, Raquel regresó dos años después a México con los cuatro hijos. Al amparo de la reforma migratoria de 1987, el marido-padre logró regularizar su situación migratoria y poco tiempo después trajo por los cauces a su esposa y a los hijos de ambos. Raquel narra que después de tantos años de separación, no solo ella y el marido se volvieron extraños sino que, a pesar de que lograron el estatus legal y la posibilidad de estar juntos, ella siente que no hay “...esa conexión...”, ese amor que debe haber entre padres e hijos, y que han quedado muchos resentimientos: "...Siempre lo respetan [refiriéndose al padre], pero como que yo siento que hay una barrera de amor [...] 
Este, emocionalmente se destruye la familia [...], Que a la larga, los hijos cuando crecen, en vez de que, este, le aplaudan el gran esfuerzo que se hizo, quedan resentimientos..."

En efecto, el resentimiento es uno de los aspectos que sobresale desde distintos ángulos en la narrativa de las entrevistas cuando se indaga acerca de la afectividad. Resentimientos de los hijos hacia las madres (y padres) por lo que sienten como abandono, de las esposas hacia los maridos ausentes, de las madres proveedoras por la pesada y prolongada carga de la manutención, de las abuelas cuidadoras, de las hijas (dominicanas) hacia los padres que las impulsaron a migrar a sabiendas del destino que les esperaba. Estos resentimientos casi nunca son verbalizados directamente. En el caso de los niños, las madres los identifican por la negativa de los menores a hablar con ellas por teléfono: “...como que siente reproche conmigo el chiquillo, dice que no soy su mamá, pero a veces dice que soy su mamá...”, reconoce Margarita, una inmigrante oaxaqueña de 23 años de edad, con tres de vivir en Nueva York. Las inmigrantes mexicanas que, como Raquel y Anastasia, son esposas, y antes de migrar estuvieron largo tiempo separadas de sus maridos, aluden tanto a la carga de trabajo que la ausencia de este representó como a la privación y contención de su sexualidad, el control sobre ellas de los suegros y la comunidad, y al lastre de lidiar con el estigma del abandono: “...yo me sentía mujer... y así lo ven a uno en el pueblo... la ven a uno como una mujer abandonada..." (Raquel); “...se sienten muchas cosas, yo ya no salía, siempre estaba ahí..." (Anastasia). También las abuelas resienten el hecho de tener que asumir el cuidado de los nietos en una etapa tardía de la vida, cuando creían finalmente tener tiempo para ellas: “...estaba acostumbrada a salirme y ahora no puedo...” (Madre de Leticia, Hidalgo, México).

Pero, junto al resentimiento, son también recurrentes las expresiones de orgullo y satisfacción por haber podido escapar de la pobreza y otorgar a los hijos una mínima oportunidad de formación escolar; o por contar con la capacidad -por mínima que esta sea- de asistir económicamente a los familiares que quedaron atrás cuando se presenta la ocasión. La mayor cuota de orgullo emana sin duda del logro que representa llegar a construir una casa propia, una meta desigualmente alcanzada por nuestras inmigrantes. El relativo empoderamiento que estas mujeres experimentan gracias a los mayores ingresos generados como trabajadoras precarias en los países de destino, eleva la autoestima personal y legitima de nueva cuenta el proyecto migratorio. Queda de manifiesto, por tanto, que en términos afectivos la migración es esencialmente una empresa que suscita sentimientos ambivalentes en la mayoría de las inmigrantes.

La diferencia que emerge en las familias transnacionales de México y República Dominicana en esta dimensión analítica, se relaciona con la mayor duración de 
las separaciones entre las mujeres mexicanas y sus familiares, y la poca frecuencia de contacto cara a cara con quienes permanecen en las localidades de origen, dado el estatus mayormente indocumentado que las distingue. ${ }^{33}$ Mientras la gran mayoría de las dominicanas viaja con cierta regularidad a su país, este resultó un escenario muy poco frecuente en las mexicanas, algunas de la cuales llevaban más de 10 años sin ver a los hijos que dejaron atrás, algo absolutamente inexistente en las dominicanas. Este aspecto, consecuencia de las distintas políticas migratorias de España y Estados Unidos como países de inmigración, hace que las secuelas negativas de la separación sean plausiblemente más profundas en las familias transnacionales mexicanas que dominicanas, a pesar de la mayor proximidad física entre México y Estados Unidos. En tales situaciones podemos pensar que el prolongado hiato de la ausencia abierto por la migración aproxima a estas familias a su fragmentación.

\section{CONCLUSIONES}

El ejercicio analítico comparativo emprendido en este trabajo ha tenido como finalidad describir las pautas de interacción de familias transnacionales de dos países latinoamericanos de emigración en dos ciudades de destino (dominicanas en Madrid y mexicanas en Nueva York), dados ciertos factores contextuales (especificidad de las corrientes migratorias, estructuras familiares de las sociedades de origen y políticas migratorias de los países de recepción). Las imágenes de la vida familiar descritas se sustentan en un conjunto de entrevistas a profundidad sostenidas con mujeres inmigrantes de los sectores manuales bajos de la fuerza de trabajo, en su gran mayoría empleadas domésticas.

La estrategia analítica perseguía describir las pautas de interacción en tres dimensiones de la vida familiar: la reproducción doméstica, la maternidad y el cuidado, y la afectividad, delineando cuando fuera posible la impronta dejada por la especificidad del grupo nacional cuyos contrastes se intentaba realzar. El análisis empírico se sirvió del momento de ciclo familiar y de la duración de la separación como recursos metodológicos que permiten introducir cierto grado de control en las observaciones. En conjunto, los resultados arrojan más puntos de continuidad que de diferencia, lo que entendemos guarda relación con la importante homogeneidad social de los dos grupos de inmigrantes contrastados: mujeres trabajadoras, provenientes en su mayoría de sectores sociales bajos e insertas en condiciones laborales precarias. En la dimensión de la reproducción doméstica quedó de manifiesto la importancia de las remesas monetarias como elemento estructurador de la

33 Solo dos de las inmigrantes mexicanas entrevistadas contaba con estatus legal (una ciudadana y una residente), situación que era prácticamente la opuesta entre las dominicana. 
interacción a distancia en familias transnacionales de bajos recursos, cuyas implicaciones en la dinámica intrafamiliar no son siempre positivas. En sí mismas, constituyen un factor de diferenciación dentro de los hogares, suscitando situaciones potencialmente conflictivas. Todas las mujeres envían remesas y estas tienden a guardar una relación de concomitancia con el momento del ciclo familiar y la maternidad, con ciertas excepciones. El hecho de que sea el principal canal de interacción favorece en ocasiones la mercantilización del afecto y abre espacios de manipulación y chantaje, en ambas direcciones.

Desde los momentos iniciales de la migración, esta deja huellas tangibles en la interacción familiar de las madres y sus hijos, las que son diferenciales según el momento del ciclo y la edad de los menores. De forma ambivalente, las madres reconocen la dificultad que implica el ejercicio de la maternidad transnacional, situación que las confronta fuertemente en virtud del peso normativo de la maternidad. Más que en ninguna otra arena, las condiciones de la maternidad a distancia dejan en evidencia la contradicción entre un proyecto migratorio edificado en pro del bienestar de los hijos y la merma que sobre este bienestar ocasiona la cotidiana ausencia física de la figura materna, de acuerdo con la percepción de las entrevistadas.

El ámbito de la afectividad suscita sentimientos ambivalentes y plantea importantes desafíos a la interacción familiar a distancia. A pesar de que la continua comunicación (esencialmente telefónica) que las migrantes de ambos países mantienen con sus familiares en los lugares de origen, sea cual sea la antigüedad de la migración, la duración de la separación puede conducir a situaciones de relativa desfamiliarización y desconexión afectiva, y a la emergencia de resentimientos que en cierto modo atraviesan las historias migratorias. Evaluada contra el rasero de la afectividad, la migración emerge como una empresa poco gananciosa a los ojos de la mayoría de las migrantes, puesto que su pérdida se antoja irrecuperable.

No obstante, cuando son los logros materiales los que se ponderan -ya sea la edificación de una casa propia (o el impulso para llegar a alcanzarla), o la posibilidad de solventar con mayor holgura que antes las necesidades materiales inmediatas de los familiares en origen-, sentimientos de orgullo y satisfacción y un relativo empoderamiento tiñen la narrativa de las inmigrantes, otorgando de nueva cuenta legitimidad al proyecto migratorio.

Estos aspectos resumen los puntos de continuidad en la interacción familiar a distancia en las familias transnacionales de los dos grupos de inmigrantes y países analizados. Las notas disonantes no dejan de ser llamativas: 1) un patrón de descapitalización y envío constante de remesas a lo largo de todo el curso de vida frecuente en las mujeres 
dominicanas jefas de hogar, que hemos hipotéticamente relacionado con el mayor peso de este tipo de arreglo familiar en la sociedad dominicana y las fuertes responsabilidades que conlleva; 2) una pauta de relevo transnacional en el envío o recepción de remesas monetarias entre los familiares dominicanos residentes en dos o tres países, atribuido al mayor grado de transnacionalidad de su sociedad en conjunto, dada la diversificación de sus destinos migratorios; 3 ) una mayor restricción hacia la movilidad laboral independiente de las mujeres en México que en República Dominicana, que hemos asociado a factores sociodemográficos y culturales de diversa índole; 4) un mayor potencial disruptor de la duración de la separación sobre la dinámica de las familias transnacionales mexicanas que dominicanas, en virtud de las mayores restricciones que al contacto físico y al intercambio familiar opone la política migratoria estadounidense en relación a la española, a pesar de la vecindad geográfica entre México y Estados Unidos.

Si bien las familias luchan con todos los medios a su alcance para preservar su unidad, situaciones de separación prolongada y ausencia de contacto físico, pueden bien colocarlas al borde de su fragmentación.

\section{REFERENCIAS}

Aja, Eliseo y Joaquín Arango, eds. 2006. Veinte años de inmigración en España. Perspectivas jurídica y sociológica [1985-2004]. Barcelona: Fundación CIDOB.

Ariza, Marina. 2002. "Migración, familia y transnacionalidad en el contexto de la globalización: Algunos puntos de reflexión." Revista Mexicana de Sociología 4:53-84.

Ariza, Marina, M. González de la Rocha y Orlandina de Oliveira. 1994. "Características, estrategias y dinámicas familiares en México, América Central y el Caribe." Informe final. Population Quality of Live Independent Comission.

Ariza, Marina y Orlandina de Oliveira. 1999. "Formación y dinámica familiar: diferencias entre México, Centroamérica y el Caribe." Pp. 165-71 en México diverso y desigual: enfoques sociodemográficos, editado por Beatriz Figueroa. México D.F.: Sociedad Mexicana de Demografía y El Colegio de México.

. 2001. "Contrasting Scenarios: Non Residential Family Formation Patterns in the Caribbean and Europe." International Review of Sociology II (11):47-61.

. 2004. "Familias, pobreza y necesidades de políticas públicas en México y Cen-

troamérica." CEPAL, Texto elaborado para la Reunión de Expertos sobre Familia, Santiago de Chile. 
. 2006. "Regímenes sociodemográficos y estructura familiar: los escenarios cambiantes de los hogares mexicanos.” Estudios Sociológicos 24 (70):3-30.

. 2007. "Familias, pobreza y desigualdad social en Latinoamérica: una mirada comparativa." Estudios Demográficos y Urbanos 22 (1):9-42.

Ariza, Marina y María Eugenia D’Aubeterre 2009, “Contigo en la distancia... Dimensiones de la conyugalidad en migrantes mexicanos internos e internacionales.” Pp. 353-94 en Tramas familiares en el México contemporáneo, coordinado por Cecilia Rabell. México D.F.: Instituto de Investigaciones Sociales-UNAM y El Colegio de México.

Ariza, Marina y Alejandro Portes. 2007. El país transnacional: migración mexicana y cambio social a través de la frontera. México D.F.: Instituto de Investigaciones Sociales-UNAM.

Báez, Carlos. 2001. Dominicanos en España, españoles en Santo Domingo. Santo Domingo: Editora Universitaria, Universidad Autónoma de Santo Domingo. UASD.

Baldassar, Loreta. 2007. "Transnational families and the provision of moral and emotional support: the relationship between truth and distance." Identities 14 (4):385-409.

Baldasaar Loreta, Cora V. Boldock y Realene Wilding. 2007. Families caring across borders: migration, aging and transnational caregiving. London: Palgrave MacMillan.

Boletín Estadístico de Extranjería e Inmigración. 2009. Padrón de empadronamiento No 20, mayo 2009. Madrid: Ministerio del Trabajo e Inmigración.

Bryceson, Debora y Ulla Vuorela. 2002. The transnational family: new european frontiers and global networks. New York: Berg Publishers.

Calavita, Kitty. 1989. "The contradictions of immigration lawmaking: the immigration reform and control act of 1986." Law \& Policy 11 (1):17-47.

2006. "Contradicciones estructurales de la política de inmigración: los casos de la Europa del Sur y de los Estados Unidos.” Revista Española de Investigaciones Sociológicas 116:195-212.

Carrillo, María Cristina 2008. "Foto de familia. Los usos privados de las fotografías entre familias transnacionales ecuatorianas. El caso de la migración hacia España." Pp. 281-302 en América Latina migrante: Estados, familias e identidades, editado por Gioconda Herrera y Jacques Ramírez. Quito: Flacso y Ministerio de Cultura del Ecuador.

Colectivo IOE. 2002. “Política migratoria en España en el marco europeo.” Mimeo, Madrid. 
D’Aubeterre, María Eugenia. 2000 El pago de la novia. Matrimonio, conyugalidad y prácticas transnacionales en San Miguel Acuexcomac. Puebla: El Colegio de Michoacán, BUAP, ICSyH.

Díaz, Magdalena. 2008. Las dinámicas internacionales de cuidado: el caso de Madrid en la desnacionalización del cuidado de menores. Madrid: Universidad Carlos III.

Domingo, Andreu y Rosana Martínez. 2006. "La población latinoamericana censada en España en el año 2001: un retrato sociodemográfico.” Notas de Población 81:99-127.

Dreby, Joanna. 2006. "Honor and virtue: mexican parenting in the transnational context." Gender \& Society 20:32-59.

. 2007. "Children and power in mexican transnational families." Journal of Marriage and Family 69:1050-1064

Durand, Jorge. 2007. “Origen y destino de una migración centenaria." Pp. 55-81 en El país transnacional: migración mexicana y cambio social a través de la frontera, editado por Marina Ariza y Alejandro Portes. México D.F.: Instituto de Investigaciones Sociales-UNAM.

Durand, Jorge y Douglas Massey. 2003. Clandestinos. Migración México-Estados Unidos en los albores del siglo XXI. México D.F.: Universidad Autónoma de Zacatecas, Editorial Miguel Ángel Porrúa.

Durand, Jorge, Douglas Massey y René Zenteno. 2001. "Mexican migration to the Unites States: continuities and changes." Latin American Research Review 36 (1):107-27.

Gonzálvez, Herminia. 2007. "Familias y hogares transnacionales: una perspectiva de género." Puntos de Vista: Cuadernos del observatorio de las migraciones y la convivencia intercultural de la ciudad de Madrid III (11):7-25.

Goulbourne, Harry, Tracey Reynolds, John Solomos y Elisabetta Zontini. 2010. Transnational families. ethnicities, identities and social capital. New York: Routledge.

Grammage, Sarah y Schmitt John. 2004. Los inmigrantes mexicanos, salvadoreños y dominicanos en el mercado laboral estadounidense: las brechas de género en los años 1990 y 2000. México D.F.: CEPAL/Serie Estudios y perspectivas 20.

Hill, Reuben. 1964. "Methodological issues in family development research." Family Process 3:186-206. 
Hochschild, Arlie R. 2001. "Las cadenas globales de afecto y asistencia y la plusvalía emocional." Pp. 187-209 en El límite: la vida en el capitalismo global, editado por A. Giddens y W. Hutton. Barcelona: Tusquets.

Hondagneu-Sotelo, Pierrette. 2001. Domestica. Immigrant workers clearing and caring in the shadows of affluence. Berkerley y Los Angeles: University of California Press.

Hondagneu-Sotelo, Pierrette y Ernestine Avila. 1997. “I'm here, but I'm there. The meanings of latin transnational motherhood." Gender \& Society 11 (5):548-71.

Instituto Nacional de Geografía, Informatica y Estadistica (Inegi). 2011a. Tabuladores Básicos, Censo de población y vivienda 2010. Consultado septiembre 12, 2011 (http://www3.inegi.org. $\mathrm{mx} /$ sistemas/TabuladosBasicos/Default.aspx?c=27303\&s=est).

2011b. Encuesta Nacional de la Dinámica Demográfica. 2009. Panorama sociodemográfico de México: principales resultados/Instituto Nacional de Estadística y Geografía, Consejo Nacional de Población. México D.F.: Inegi.

.2011c. Principales resultados del censo de población y vivienda 2010. Instituto Nacional de Estadística y Geografía. Consultado septiembre 22, 2011 (http://www.censo2010. $\operatorname{org} \cdot \mathrm{mx} /$ ).

Levitt, Peggy. 2001. The transnational villagers. Berkerley y Los Angeles: University California Press.

Maguid, Alicia. 2008. La emigración internacional a través de los censos en países de origen: evaluación de resultados y recomendaciones. Chile: CEPAL/Serie Población y Desarrollo 86.

Margulis, Mario. 1988. "Reproducción de la unidad doméstica, fuerza de trabajo y relaciones de producción." Pp.189-215 en Grupos domésticos y reproducción cotidiana, editado por Orlandina de Oliveira, Marielle Pepin Lehalleur y Vania Salles. México D.F.: Porrúa, El Colegio de México, Colección Ciencias Sociales.

Mier y Terán, Marta. 2009. “El proceso de formación de las parejas en México.” Pp. 199-25 en Tramas familiares en el México contemporáneo, coordinado por Cecilia Rabell. México D.F.: Instituto de Investigaciones Sociales-UNAM, El Colegio de México.

Oso, Laura. 1998. La migración hacia España de mujeres jefas de hogar. Madrid: Ministerio del Trabajo y Asuntos Sociales, Instituto de la Mujer. 
Parella, Sonia. 2007. “Mujeres inmigrantes en el mercado de trabajo español." Pp. 361-86 en Mujeres, instituciones y política, editado por Isabel Diz y Marta Lois. Barcelona: Edicions Bellaterra.

Passel, Jeffrey. 2004. "Estimates of the size and characteristics of the undocumented population.” Pew Hispanic Center. Consultado febrero 20, 2011 (http://pewhispanic.org/files/reports/44.pdf).

Passel, Jeffrey y D’Vera Cohn. 2009. “A portrait of unauthorized immigrants in the United States." Pew Hispanic Center. Consultado febrero 19, 2011 (http://pewhispanic.org/files/reports/107.pdf).

Pew Hispanic Center. 2009. "Mexican immigration to the United States, 2008." Washington, D.C. Consultado abril 12, 2010 (www.pewhispanic.org).

Pribilsky, Jason. 2004. “Aprendemos a convivir': conjugal relations, coparenting, and family life among ecuadorian transnational migrants in New York city and the ecuadorian Andes." Global Networks 4 (3):313-34.

Salazar, Rhacel. 2001. Servants of globalization. Women, migration and domestic work. California: Stanford University Press.

. 2002. "The care crisis in the Philippines: children and transnational families in the new global economy." Pp. 39-54 en Global women: nannies, maids, and sex workers in the new economy, editado por B. Ehrenreich y A. R. Hochschild. New York: Henry Holt and Company, LLC, Publishers.

.2005. Children of global migration. Transnational families and gendered woes. Stanford: Stanford University Press.

Sánchez-Carretero, Cristina 2005. "Motherhood from Afar: channels of communication among dominican women in Madrid." European journal of international migration and ethnic relations 43:145-64.

Schmalbauzer, Leah. 2004. "Searching for wages and mothering from afar: the case of Honduran transnational families." Journal of marriage and family 66 (5):1317-331.

Segob. 2010. Boletín No 195/10. Dirección general de comunicación social. México: Boletín de Prensa. 
Skrbis, Zlatko. 2008. "Transnational families: theorising migration, emotions, and belonging." Journal of intercultural studies 29 (3):231-46.

Solís Patricio e Ismael Puga. 2009. "Los nuevos senderos de la nupcialidad: cambios en los patrones de formación y disolución de las primeras uniones en México." Pp. 158-76 en Tramas familiares en el México contemporáneo: una perspectiva sociodemográfica, editado por Cecilia Rabel. México D.F.: IIS-UNAM, El Colegio de México.

Sørensen, NInna. 2004. "Narratives of longing, belonging and caring in the Dominican diaspora." Pp. 222-43 en Caribbean narratives, editado por J. Besson y K. F. Olwig. London: MacMillan.

Thomas, William y Florian Znaniecki. 1927. The polish peasant in Europe and America. New York: Knopf.

Tuirán, Rodolfo. 2001. “Dinámica reciente de la migración México-Estados Unidos.” Mercado de Valores LXI:3-26.

Yeats, Nicola. 2005. "Global care chaind: a critical introduction." Global migration perspectives 4:1-19.

Zúñiga Elena, Paula Leite y Alma Nava. 2004. La nueva era de las migraciones. Características de la migración internacional mexicana. México D.F.: Consejo Nacional de Población. 